\title{
Focus: Current issues in medical ethics
}

\section{The 'no lose' philosophy in medicine}

\section{S Galbraith Department of Neurosurgery,} Institute of Neurological Sciences, Glasgow

This article as the series title suggests focuses our attention on decisions, both medical and ethical, which face doctors and related personnel in the medical profession daily. Many of these decisions take the form of a choice to do one thing or another without being very sure of the outcome of either action. $\mathrm{Mr}$ Galbraith explores the pros and cons of what he calls the 'no lose' philosophy in medicine and which plays a large part in medical decision making. He concludes that possibly we may need a new philosophy rather than continuing to use more and more of our resources on care, which is perhaps being carried out as a means of avoiding making value judgments and thus possibly, prevents us from solving some of today's difficult ethical problems.

'Yes, but you must wager. There is no choice, you are already committed. Which will you choose then ? Let us see: since a choice must be made, let us see which offers you the least interest. You have two things to lose: the true and the good; and two things to stake: your reason and your will, your knowledge and your happiness; and your nature has two things to avoid: error and wretchedness. Since you must necessarily choose, your reason is no more affronted by choosing one rather than the other. That is one point cleared up. But your happiness ? Let us weigh up the gain and the loss involved in the calling heads that God exists. Let us assess the two cases: if you win you win everything, if you lose you lose everything. Do not hesitate then; wager that he does exist.'

Pascal

Pascal $^{1}$ used probability to justify belief in God; if God did exist then everything was gained, if $\mathrm{He}$ did not, then at least nothing was lost. As Seigler ${ }^{2}$ has emphasised this form of reasoning is often used by doctors when predicting the outcome of an individual's illness. The doctor may inform the relatives that the patient will die, and if this happens, nothing is lost. Should the patient survive however, the relatives' gratitude will be greater and for the doctor everything is won. This is the philosophy of 'no lose' and in this situation Seigler has called it the 'hanging of crepe'. I hope to show, however, that not only is this attitude even more widespread in medicine than Seigler has suggested, but also that contrary to Pascal's reasoning, it is a philosophy with considerable potential for loss not only in the present but also well into the future. Even more important, I also hope to show that it is used as a means of avoiding value judgments and thus prevents us from solving some of today's difficult ethical problems.

\section{Examples of 'no lose' in medicine}

In the investigation of patients it is sometimes held that all available information is required before coming to a diagnosis. In this way, it is hoped to strengthen the diagnosis, identify rare conditions or confirm normality. As much information as possible is collected before a diagnosis is reached. This is 'no lose'. Let us take as an example (and I must apologise for using only neurological examples) the case of the patient presenting with classical migraine. 'No lose' requires that the patient have a lumbar puncture, a scintiscan, an EMI scan and an angiogram, unnecessary and sometimes dangerous investigations, all done in order to ensure that the symptoms are not due to an arteriovenous malformation, the chance of which is so small as to be negligible. Already we begin to see some of the problems that present when such a policy is carried out in patients presenting with migraine.

A similar situation occurs with treatment, which is often prescribed on the basis that it may be of benefit and if not, then at least it is unlikely to do harm. Like Pascal, probability is used to justify this; the probability of good, though small, is definite, the probability of harm is nil. This is particularly liable to apply to conditions which have a high mortality such as severe head injury in which the philosophy of 'no lose' maintains that in such a situation any treatment, however expensive, elaborate or unproven, is justified. Patients with severe head injury are often put on a respirator and given various drugs, even although we know they are of no value. Physicians continue to prescribe them purely on the basis that even if they do no good then at least they do no harm and therefore nothing is lost. 


\section{Advantages of 'no lose'}

As in Seigler's original example, the physician often benefits from 'no lose'. Undertaking elaborate but unnecessary investigations can create an impression of competence and intelligence. The obscure investigation, even if negative, at least prevents the doctor from being wrong. Just as important, it removes the necessity for making a decision, an action to which many doctors are unsuited.

For the patient 'no lose' maintains that he or she will benefit if all possible investigative techniques or therapeutic measures are used even if the probability of diagnostic or therapeutic success is low. If all possible investigations are done, theoretically at least, extremely rare conditions will be unearthed, the discovery of which will be of benefit to the patient. If all possible treatments are given again theoretically at least, the rare patient may make an unexpected (a paradox in itself) improvement and the treatment therefore will have been of benefit to that patient.

\section{Disadvantages of 'no lose'}

The morbidity and mortality from an unnecessary diagnostic procedure may exceed the benefit likely to be derived from the discovery of a rare or unexpected disease. ${ }^{3}$ Patients having cerebral angiography are at considerable risk of developing complications; haematoma in the neck, paralysis, blindness and even death. If one of these complications occurs in a person being investigated for a benign headache in order 'not to lose' then indeed that patient has certainly lost.

In the same way, unnecessary treatment can be a disservice to the patient, exposing him or her to discomfort, hazard and in some countries unnecessary expense. As I have previously mentioned, patients with severe head injury are often vigorously treated since this is considered a 'no lose' situation. Unfortunately, as a result of this treatment many patients survive in a vegetative state; they lie in bed performing only vegetative functions and never appreciate or make contact either with people or their surroundings. Certainly here the wager has been lost, as most people consider that death would have been a better outcome. ${ }^{4}$

There are also indirect disadvantages to the patient which occur as the result of the society in which we live. Treatment can create conflict between the needs of the individual and the needs of society, since one patient's unnecessary investigation or treatment may prevent another patient's necessary investigation or treatment. As Hiatt ${ }^{5}$ has said, we must protect the medical commons. When only a few used unlimited resources then there could be complete freedom, but resources being finite, unlimited freedom in medicine can now only be at the expense of others.

Physicians themselves do not escape from the disadvantages of 'no lose'. A stereotyped 'no lose response to a given situation makes the physiciant less able to deal with different situations presenting in the future. The physician acting in this way, wiff. not only lose 'the true and the good' but also 'you䍃 reason and your will, your knowledge'. It appears that even in this, Pascal may have been wrong.

Finally, let me return to Seigler's original examplof 'no lose' since it is really only today that we are beginning to realise the considerable long term disadvantage of this philosophy. Relatives have become so used to doctors wrongfully predictin $\vec{g}$ death that now when we can predict the outcome in patients with severe head injuries the prediction often disbelieved. Relatives insist on continuing treatment and as a result patients with severe hea injuries who would normally die, survive in vegetative state with all the psycho-social and economic problems involved. No one has won, everyone has lost.

\section{On confusing ethics with mathematics}

Probably the greatest disadvantage of the 'no lose् philosophy is that it prevents us from dealing wits our ethical problems. Doctors often need to make management decisions based on value judgements particularly decisions concerning the prolongatio of life and the quality of life. By their very nature these decisions are difficult and if possible we see ways around them. The management decision is based on the answer to the first question, the preser? vation of life, while it itself is dependent on the answer to the second question, the quality of life The ethical decision therefore only concerns thie quality of life. If, however, we can answer the first question without dealing with the second question then we can make a management decision without making an ethical decision. 'No lose' allows us to do this. What we do is commit the 'no lose slide? we reinterpret value judgements in terms of matheo matical probability and by applying Pascal's 'n lose' wager, avoid the ethical problem.

Let us take, as an example, the patient with malignant brain tumour; should we prolong life ap all costs and what of the quality of life? An answerto to the first question, and therefore a managementu decision, is provided by applying the 'no lose slide $\sigma$ The wager insists that life is prolonged at all costso just in case a cure is obtained; in any event, nothing will be lost. It is important to realise, however, and I must emphasise this, that although the decision is often expressed in moral terms, it is, in fact, no a moral decision. Nothing has been said about th basic value judgements involved, in particularof about the quality of life. 'No lose' has allowed us to make the management decision, it has not solved the moral dilemma.

Returning once again to another example witk which I am most intimately involved, the person witio 
a severe head injury. As I said, it is now possible to predict the outcome of an individual patient; whether they will live or die and if they live, what sort of existence they can expect. ${ }^{6}$ Head injury, however, unlike malignant disease, is not always terminal and any mistake would be more serious; failure to treat a patient with malignancy would terminate life, at the most, a few months earlier but failure to treat the patient with a head injury could terminate life many years prematurely perhaps even 'four score years and ten'. However, any attempt to avoid this mistake by prolonging life results in many patients surviving, if not in a vegetative manner, then at least severly disabled. A further problem is then added to the dilemma; is one normal life worth many useless lives? The answer to this question as with that on the preservation of life is dependent on a solution to the question concerning the quality of life. Again, however, we can evade solving this fundamental problem by using the 'no lose slide' which, in this situation, works even more effectively. Since a wrong decision has even greater consequences than in malignant disease, the wager insists on the preservation of life. The ethical dilemma, the quality of life remains unsolved.

Ethics attempts to deal with fundamental moral problems and if these cannot be answered then at least it suggests ways of dealing with the situations in which the moral dilemmas present. The methods for dealing with these problems are even more attractive if expressed in mathematical terms since this not only gives them an air of respectability but also opens them to the possibility of empirical verification. The ethic of 'no lose' has all these advantages. However, it must be remembered that even as Pascal's wager does not answer the question of God's existence so to the ethic of 'no lose' does not answer the ethical questions involved in the practice of medicine. All it does is provide a behavioural response but by doing so prevents a solution to the basic ethical dilemma.

"The definition of a "hopeless cripple" . . . will not be easy, for it will depend on the value judgements of people, not on the calculations of computers'. ${ }^{7}$

\section{Conclusions}

The justification for a 'no lose' philosophy is that it 'may be' that certain events will occur. It 'may be' that an investigation will show a brain stem abscess.
It 'may be' that the patient with an acute lumbar disc and weak foot (a common disease) has porphyria (a very uncommon disease). It 'may be', although it has never happened, that the 70-year-old patient with fixed dilated pupils who is unresponsive to pain and not breathing, will make a good recovery. The probability in all cases is solow, however, that doctors ought to resist the temptation to follow such an unlikely possibility just in case. Investigation and treatment must have limits, otherwise the 'no lose' philosophy is liable to become a 'lose' philosophy, with more and more money being spent on an increasing number of negative investigations and useless treatments. The United States of America spends three times the amount of money per head of population in medicine than Britain but, by any measurable index of health, has a poorer system of care. Medicine has become more and more expensive and is now outgrowing the financial resources available. 'Emphasis will have to be on making the best use of available resources and applying them where they are most needed and where they make the most impact'. 8 The greatest opposition to this comes not from society but from doctors and their application of a 'no lose' philosophy.

Within a short time of Pascal proposing his wager a number of arguments were produced showing that it was in fact a losing wager; God may not like people who believe in Him, merely because they feel they cannot lose. Similarly, I hope I have shown that in medicine also, Pascal's wager may be a 'lose' situation, detrimental to the overall delivery of health care. In particular, I think it is the major reason for our failure to deal with some of the ethical dilemmas facing us today. Medicine is at the crossroads with more and more being spent for less and less. It may not be more money that is required; it may be a new philosophy.

\section{References}

1Pascal, B (1976), Pensées, translated by A J Krailsheimer. London, pp. 149-155, Penguin.

'Seigler, M (1975), New England fournal of Medicine 293, 853-857.

${ }^{3}$ McLamb, J T, Huntley, R R (1967). Southern Medical fournal, 60, 469-472.

${ }^{4} J$ ennett, B (1976). Archives of Neurology. 33, 595-597.

'Hiatt, H U (1975). New England fournal of Medicine, 293, 235-24I.

'Jennett, B, Teasdale, G, Braakman, R, Minderhoud, J, and Knill-Jones, R (1976). Lancet, I, I03I-I034.

'Editorial (1973). Lancet, I, 523-524.

${ }^{8}$ Editorial (1975). British Medical fournal, 4, 723. 